\title{
A SYSTEMS VIEW OF THE IST VALUE CHAIN: THE PROCESS-VALUE MODEL
}

\author{
William L. Lomerson, Northwestern State University, lomersonw@nsula.edu \\ Bin Mai, Northwestern State University, maib@nsula.edu
}

\begin{abstract}
In this paper, the authors propose a new framework, the Process-Value Model (P-VM), to investigate the mechanism through which IST contributes to the organization's business value generation. The P-VM is based on General System Theory and describes the IST value chain, which directly relates the IST process to the production of measurable business outcomes. The model resolves one essential limitation of existing theoretic models, namely the lack of an effective core framework for identifying the underlying IST system and its relationship to the business organization performance objectives. PV-M provides a solid platform for further research into the mechanisms by which IST contributes to enhancing business performance.
\end{abstract}

Keywords: IST, productivity paradox, General System Theory, IS value chain, business value, IS evaluation, IST value

\section{INTRODUCTION}

More than 15 years have passed since the productivity paradox was raised as an issue of central concern to the IST research community and it still remains largely unresolved. Information Systems and Technology (IST) researchers have proposed a variety of methodologies adopted from the finance, accounting and management disciplines [7, 8, 23, 31] in attempts to evaluate the contribution of ITS to organizational performance but most efforts have been selectively limited and/or lack a basis for effective generalization. However, the process by which IST contributes to the organization's effort to generate value for the end consumers remains a hot debate among both industry practitioners and academic researchers alike $[11,26]$. The authors suggest that the essential problem lies in the lack of an effective core framework for identifying the underlying IST system and its relationship to the business organization performance objectives.

The authors propose a new framework, the IST Process-Value Model (P-VM), to describe the IST value chain and thereby directly relating the IST process to the production of measurable business value. General System Theory is used to provide the basic framework and descriptions of interacting system to develop and analyze the IST value chain and the P-VM in organizations. The model views the IST system as one of many subsystems that comprise the system known as the business organization. The proposed P-VM illustrates how the IST system interacts with other business subsystems to contribute to the overall process of generating business value.

The P-VM resolves many of the limitations of existing theoretic models and can serve as a platform for further research into the mechanisms by which IST contributes to enhancing business performance.

The rest of the paper flows as follows. In Section 2, the authors survey the literature and summarize the existing works on IST evaluation. Section 3 contains a summary of General System Theory (GST), which provides the foundation used to derive the P-VM. The P-VM is illustrated and described in Section 4. The authors discuss the importance of the model in Section 5. In Section 6, the authors discuss the difference of the proposed model and other existing models for IST evaluation and highlight the strengths of the proposed model. Section 7 contains the summarized contributions of the current paper and discussion of possible future research.

\section{Other Existing Models}

The investigation into the value of IST to a business organization has been a topic of interest almost since the inception of Information Systems as an academic field [7]. People are intrigue by the idea of determining IST's contribution to the value creation processes of business organizations, or, alternatively, how to define and measure "information systems success" in terms of creating business value.

Along the way, researchers have proposed various approaches and methodologies for addressing this important issue. In this section, the authors give an overall introduction to the existing models of IST evaluation and discuss the necessity of a paradigm shift for continuing research on this topic.

The ubiquitous presence of IST and its ever-evolving underlying technology have long demanded that business organizations have a clear vision how IST contributes to the value creation process of the organization. However, contradicting empirical evidence has been presented regarding the 
contributions of IST to the creation of organizational value $[3,4,10,22]$. There is no consensus on whether or not an organization's productivity is increased with the deployment of IST. However, it seems unlikely in today's business world that a business organization could survive a single day without an effective and efficient Information System and Technology function. This is the "productivity paradox" that has long puzzled both researchers and practitioners.

One of the first attempts at formally modeling the contribution of IST is [7]'s "Information Systems Success" model, which was updated by them in 2003. In their model, Delone and McLean introduced a comprehensive taxonomy of IS success that includes six major dimensions (in their 2003 update, an additional dimension is added). Their model was adopted by several researchers for application $[9,21]$ or empirical [25] validation. While this model is successful in dissecting the concept of "IS success", it does not treat IST as an integral element of the business organization's value creation process, and thus does not sufficiently address the issue of how to relate the "success" of IS to the business outcomes of the organization, which eventually produce business value.

Several researchers have identified various issues that complicate the issue of information systems evaluation. [13] noticed that "a strategic competitive advantage will not be achieved through embraced technology alone but, in the way companies approach the evaluation, management and exploitation of their human, organizational and technology based assets and infrastructure". In pursuing this research path, [28] adopted Process Theory to synthesize the models of IT investment evaluation, and signified the importance of "IT use and know how as intermediate outcomes". [20] developed a model of IT business values based on the resource-based view of the firm, and highlighted their principle result that IT values "are dependent upon internal and external factors, including [among other factors] complementary organizational resources of the firm..." While these research efforts have provided valuable insights to the value of IST, their main focus is primarily on IST function and processes themselves; not on how they are integrated with the business organization's value creating processes.

Other researchers have started integrating the value of IST into the process of the business organization creating business values. [18] introduced the term "productiveness" to complement the evaluation of IT performance in terms of productivity, effectiveness, and efficiency. Based on that result, [5] proposed a framework for performance evaluation based on the consumer originated values. In their value-based framework, performance measures are determined from the consumer value the business organization provides from the outcomes it produces. The combined value of all of the outcomes generated by a business gives a total value for all of the activities of a business. Based on this framework, [17] also proposed a model that illustrates how IST contributes to organizational value. This effort established a general link of the IST-based activities to the organizational value creation effort, as well as providing a preliminary description of this IST value chain.

In this paper, we extend the work on the stream of research that studies IST contributions within the context of value-generating processes of organizations. We use General System Theory (GST) as the basis for developing a descriptive model of the IST system within the business organization. The resulting IST Process-Value Model (P-VM) depicts how the IST system and IST processes, together with other business processes, create business outcomes, which in turn generate consumer value.

\section{SUMMARY OF GENERAL SYSTEM THEORY}

GST was first proposed by Ludwig von Bertalanffy in 1945 [2] as an analytical approach for investigating complex entities, which he called systems, that are comprised of multiple interdependent and interacting components working to achieve a common purpose. These systems include physical, mechanical, biological, economic and social entities. GST provides a framework for clearly identifying the subject entity, creating a formalized model of the entity and thereby enabling the ability to study the entity. More importantly, it allows independent researchers to identify similar entities on which to conduct comparable studies. While a descriptive model may lack the rigor of a mathematically grounded model, it can provide the basis for future formalization and is better than no model at all [2, p. 24].

An IST system is an archetypical example of a system that conforms to the posits of GST. Several recent IST studies have sought to bring some of the principles of GST directly into their research. [12] draws on many of the tenets of GST to examine the nature of theory in IST. [24] used GST to provide a framework for understanding the consistent misallocation of corporate resources to it is IST function by Texaco's management with regard to the actual contribution to Texaco's operational success. 
[16] used GST to construct a mathematically formalized information systems theory. None of these studies, however, have successfully provided a methodology to identify a basis for successfully measuring the performance contribution of IST to an organization's success. The authors believe that the lack of an effective descriptive IST model based upon the premises of GST is a significant contributor to this lack of success. To effectively formulate an IST model based upon GST, it is essential to understand the fundamental elements of GST. These can then be used as the foundation for a comprehensive IST model.

The basic posit of GST maintains that every open system exists in a continuum of other open systems. Every system is a sub system of its parent system and is the parent of its own sub systems. A system is defined by its boundaries between and its interactions with its parent system. The boundary must clearly define those components that constitute the system and separates them from its environment, which is everything outside the system and, in fact, may be another well defined system. In particular, the system boundaries are defined by the points at which elements within the system exchange energy, information and/or resources with elements outside the system. After the boundary has been defined, appropriate inputs, outputs and outcomes can be identified. (This concept is illustrated in Figure 1.) These factors enable units of analysis or measurement systems to be defined that form the basis for performance analysis of the system. [27, p. 27]

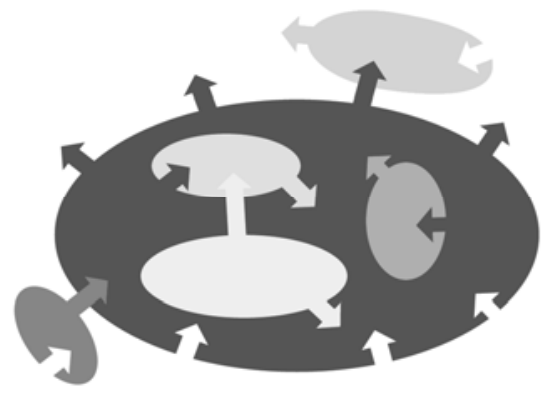

Figure 1. GST Systems Contiuum

[29] has demonstrated in his empirical research project that knowledge management is a critical organizational capability through which IST influences firm performance. In GST terms, knowledge managers (IST consumers) represent the key point of interaction between the IST system and its parent environment, the business organization.
These IST consumers, supported by the IST interaction, then work with other components of the business system to acquire the resources to support the business processes and to produce the outcomes that represent business performance. These outcomes provide the points of interaction for the business system with its consumer environment and generate the ultimate value sought by the organization. This concept is illustrated in Figure 2.

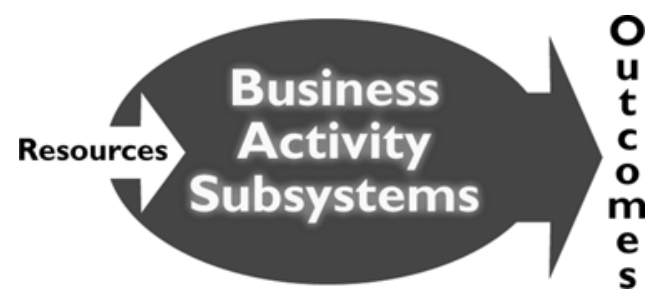

Figure 2. GST Model of a Business

The preceding discussions and research findings provide the foundation for the IST Process-Value Model described in the following paragraphs.

\section{THE PROCESS-VALUE MODEL (P-VM) FOR IST EVALUATION}

An important consequence of the P-VM is the readily identifiable value chain associated with IST system's products and services. Using this value chain, it is possible to determine the cost-benefit of producing any outcome and the IST system's contribution to the process. The overall model is presented in Figure 3 and described in the following paragraphs.

As stated previously, the ultimate goal of a business organization, which is itself a system, and thus of its subunits and processes, is to create outcomes that generate consumer value, the end point of the value chain. More importantly, however, is the fact that the outcomes sought by IST are the same outcomes being sought concurrently by the other subsystems within the organization. The demarcations and interactions between the IST system and its parent system, the business organization, and between the parent system and its key exchange point, the consumer, are clearly shown in the $\mathrm{P}$ VM.

The business organization system boundary is identified by the bold dashed line encompassing various entities and processes, among which are the IST system and the IST function. The User represents the interaction of IST with all the other processes (subsystems) in the organization. 


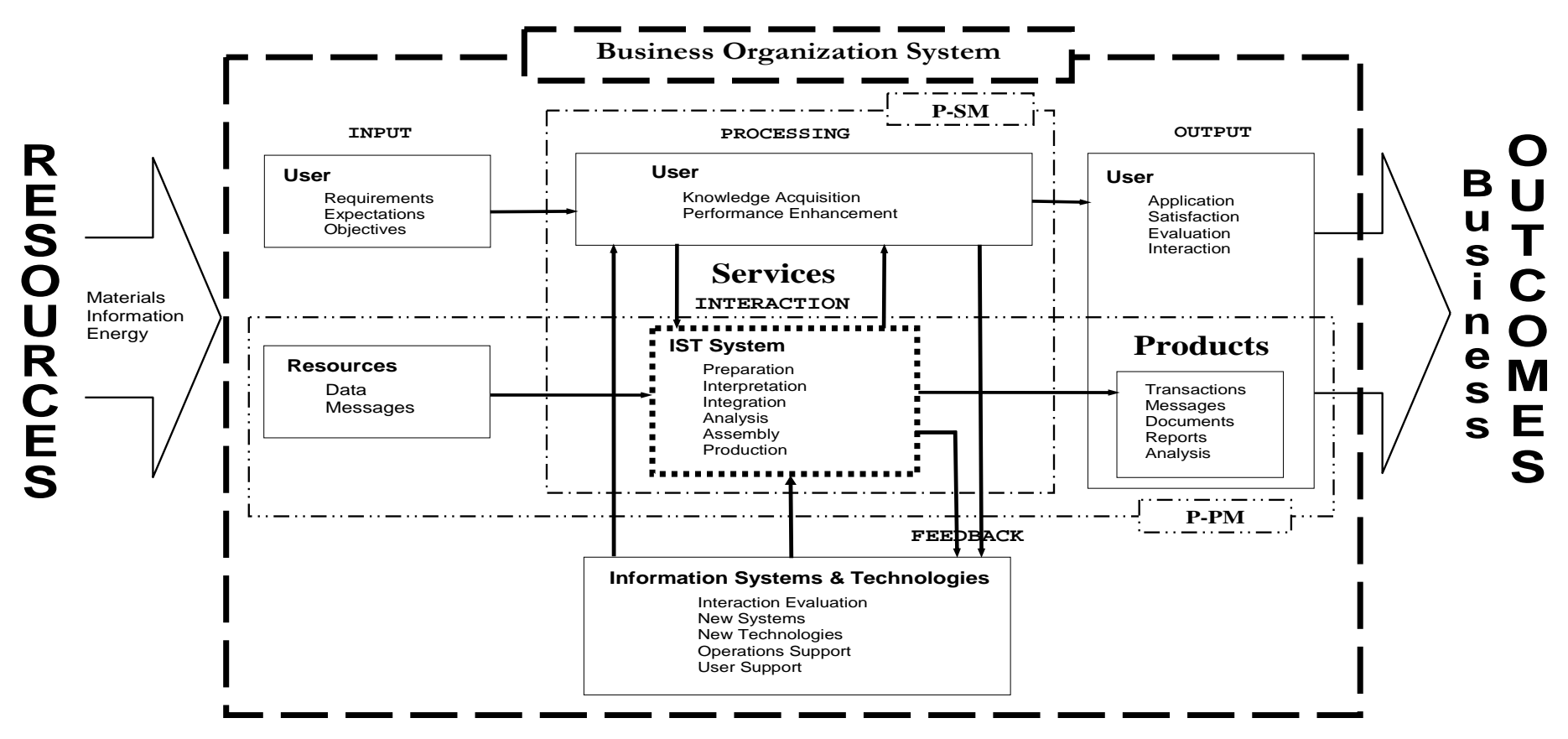

Figure 3. Process-Value Model for IST Evaluation

The P-VM emphasizes two main issues of IST evaluations that have remained ambiguous in previous research. First, it clarifies the fact that all consumer values generated by the business organization in general, including those directly enabled by IST in particular, are realized only through the business outputs of the organization. Thus the P-VM explicitly identifies the link of business output as an intermediary between the business organization system and consumer values. Secondly, it demonstrates that IST products (i.e., the actual software systems) play a critical role in the business organization's value generation by direct facilitation of the business processes that result in producing business outcomes. It further clarifies the product (generating the organization's IST systems) and service (developing, maintaining and supporting the systems technology) roles of the IST function within a business organization., By identifying the mechanism through which IST participates in the various business processes, the P-VM provides the framework to isolate and, thus, measure the contribution of IST in creating the value producing outcomes of a business organization.. As a consequence, the value of IST to a business organization can be determined and evaluated.

The remaining subsections discuss the constituent IST components of the P-VM that are part of the business organization system.

The Core: IST Process Models (P-PM and P-SM)
At the core of the P-VM are two sub-models for IST processes. The first is the traditional model of IST, the Process-Product Model (P-PM, represented by the horizontal box defined by the dash-dot-dot line in the center of the Figure 3) representing the input-processoutput function of producing information products, which was the original model used to illustrate the functionality of early IST systems [14, p. 5]. Within the context of a business organization, the process portion of the P-PM conducts preparation, interpretation, integration analysis, assembly, and production processing of collected data and new data inputs. The outputs associated with the P-PM include various information products including transactions, messages, documents, reports, and analysis. In many respects, the P-PM model still constrains the vision of many IST researchers.

The second model is the largely unacknowledged Process-Service Model (P-SM, represented by the vertical box defined by the dash-dot line, also, in the center of Figure 3) that illustrates the supporting interaction of the IST system with the Information Consumers in the organization. In this context, the PSM shares common input and processing functions with the P-PM. The differentiating function of the model is the interactive support of knowledge acquisition and performance enhancement for information consumers as they perform their roles in the creation of business outcomes. 
The need to distinguish these two sub processes is based upon the inherent difference in the natures of a service process and a product process. The first significant difference is the nature of the outcomes. With a service process, the service outcomes are produced and consumed on demand from the user; the service cannot be stored or accumulated. For a product process, the outcomes are produced in anticipation of demand from the user; the product can be stored or accumulated. The second significant difference is the user is actively and voluntarily involved in instantiating and acquiring the services provided by the service process. In the product process, the user has no role in the production of the information product. This service function has been acknowledged by some researchers as the most import contribution of the IST system to successful organizational performance [15, 29].

\section{The Support Elements for the IST Core}

To enable an IST system with its attendant processes, we must, also, have the personnel, technology and software to construct, operate, maintain and support it. These capabilities are supplied by the IST function, represented by the box defined by the solid line at the bottom of Figure 3. IST activities and processes include interaction evaluation, new systems development, new technologies implementation, operations support and user support. In addition to supporting the IST system, IST also supports the physical technologies and systems that collect data and support user interaction. The user flow channel represents the user activities within the organization that occur that enable the users to achieve the outcomes expected from them. In advance of engaging the user interaction process, the user develops internal inputs of requirements, expectations, and objectives that guide their interaction with the IST system. The result of the IST interaction produces internal outputs including application, satisfaction, evaluation, and interaction along with producing the outcomes expected by the business organization. The successful creation of desired outcomes leads to the creation of consumer value.

\section{IMPORTANCE OF THE P-VM}

The missing feature in much of the IST evaluation research has been the ability to identify an outcome that can effectively be used to measure IST performance. The P-VM illustrates a value chain for IST that leads to the same outcomes that have already been established by organizational management as the objectives of the organization. Consumer Value has the unifying ability to provide the same measurement criteria to all outcomes of the organization whether they are tangible or intangible [5]. However, once an outcome has been identified, alternate measurement approaches can be used. A recent article in Information Week [6] identified 12 different metrics that are currently being used by IST practitioners to evaluate various aspects of IST performance. None of these metrics were tied directly to organizational performance. Once a desired business outcome has been identified, performance enhancement can be both predicted and, subsequently, evaluated. Measuring the outcome before and after the enhancement shows the performance improvement achieved by the IST project. The value of the improvement compared to the cost of achieving the improvement provides the basis for performance evaluation [18].

\section{COMPARISON BETWEEN P-VM AND EXISTING IST EVALUATION MODELS}

One distinct characteristic of the $\mathrm{P}-\mathrm{VM}$ is that it treats IST as one component of the business organization's value chain. By integrating IST into the business process by which the organization generates business values for the customers, we are able to provide the first step towards a new approach to tying the contributions of IST directly to the increased value of the business process.

In earlier literature about IST evaluation, simple financial indicators have been used to estimate the IST value [32, 30, 1] without isolating the IST impacts from other elements on the financial performance. Later, other researchers started to study IST value as IST assets comprising the applications portfolio, IT infrastructure, and user skills [19]. In this stream of research, IST has been treated as a static element that incorporates various facets, rather than a dynamic component that is integrated in the value generation process of the business organization.

P-VM identifies the critical issue of IST evaluation research, the link between IST and business value generation. The P-VM explicitly links IST to the value chain of the business organization and the value of the associated business outcomes. The $\mathrm{P}$ $\mathrm{VM}$ provides the necessary framework for developing methodologies to evaluate IST performance from a dynamic and practical point of view.

\section{SUMMARY AND IMPLICATIONS FOR FUTURE RESEARCH}


The quest for effective performance evaluation of IST systems has been and continues to be an important activity for IST research. The ability to demonstrate conclusively and objectively that IST contributes positively to business performance has thus far eluded researchers. As the apparent importance of IST continues to grow and its pervasiveness continues to increase, the importance of this quest for IST researchers and professionals remains undiminished.

Various approaches have been proposed, and various models have been constructed to model the business value for IST. Unfortunately, those different models often yielded vastly different, and in many cases, contradicting results and implications. This resulted in what is called the "productivity paradox" of IST. New approaches to investigating the value of IST to the business organization are required and a new paradigm for determining the nature of IST's contribution to the business organization's value generating processes is essential.

In this paper, the authors propose a new model of the IST value chain based on general system theory (GST). In the proposed Process-Value Model (P$\mathrm{VM})$, the IST system within the business organization and the IST function exist as integral, but separate, components of the business organization system, whose purpose is to generate business outcomes that produce consumer value. The P-VM appears to overcome most, if not all, of the limitations of other existing models, and is able to directly link the IST system into the other value chains of the business organization. This approach provides significant implication with regard to the ability to identify the value of IST's contribution to organizational performance and establishes a solid foundation for further investigation to this critical, yet currently unclear, issue.

Our model presents the first step towards a new approach to study the value of IST to a business organization. The authors are currently working on several important extensions of the P-VM, with the ultimate goal of a comprehensive and operational model to effectively and accurately determine the contribution of IST to business performance.

Currently, the proposed PVM is a descriptive model based on GST that illustrates an IST system and its interaction with the other subsystems within a business organization system. While this model presents a critical foundation for understanding the value of IST to the business organizations, the next step would be use the underlying rigor of GST to translate the P-VM into an analytical model that allows rigorous analyses and valuation.

Using the resulting analytical model a set of proper and practical metrics can be developed to operationalize the actual quantifying variables required for the model. Ultimately, the goal of the authors is to develop a comprehensive methodology that enables the evaluation of IST performance.

\section{REFERENCES}

1. Bender, D. "Financial Impacts of information processing,” Journal of MIS, Vol. 3, No. 2, 1984.

2. Bertanlanffy, Ludwig von, General System Theory, George Braziller, New York, 1968.

3. Brynjolfsson, E. and L. M. Hitt, "Productivity, business profitability, and consumer surplus: three different measures of information technology value,” MIS Quarterly, 121 -142, June 1996.

4. Brynjolfsson, E., "The productivity paradox of information technology," Communications of the ACM, Vol. 36, No. 12, 67 - 77, 1993.

5. Byus, K. and W. Lomerson, "Consumer originated value: a framework for performance analysis,” Journal of Intellectual Capital,” Vol. 5, No. 4, 464-477, 2004.

6. Charbow, E., "Metrics,” Information Week, 4149, October 23, 2006.

7. DeLone, W. H. and E. R. McLean, "Information systems success: the quest for the dependent variable,” Information Systems Research, Vol. 3, No. 1, 60 - 95, January 1992.

8. DeLone, William H. and McLean, Ephraim R. "The DeLone and McLean Model of Information Systems Success: A Ten-Year Update.” Journal of Management Information Systems; Vol. 19 Issue 4, 9-30, Spring 2003

9. DeLone, W. H. and E. R. McLean, "Measuring e-commerce success: applying the DeLone \& McLean information systems success model," International Journal of Electronic Commerce, Vol. 9, No. 1, 31 - 47, Fall 2004.

10. Drucker, P. F., "The new productivity challenge,” Harvard Business Review, 69 - 79, Nov. - Dec. 1991.

11. Galliers, B., "Forward," in D. Remenyi, M. Sherwood-Smith, and T. White eds. "Achieving maximum value from information systems: a process approach,” John Wiley \& Sons, 1997.

12. Gregor, S., "The Nature of Theory in Information Systems,” MIS Quarterly, Vol. 30, No. 3, 611-642, 2006.

13. Irani, Z., M. Themistocleous, A. Gunasekaran, P. Love, and G. Khalifa, "Information Systems 
Evaluation: mini-track introduction," Proceedings of 7th American Conference on Information Systems, 2001.

14. Laudon, K.C. and Laudon, J.P. Business Information Systems, (2nd ed.). The Dryden Press, Orlando, FL, 1993.

15. Leibs, S. "A step ahead: Economist Erik Brynjolfsson leads the charge toward a greater appreciation of IT,” CFO IT, 38-41, Fall, 2002.

16. Lerner, V. S., "Introduction to information systems theory: concepts, formalism and applications," International Journal of Systems Science, Vol. 35, No. 7, 405-424, 2004.

17. Lomerson, W. and Tuten, P., "Examining evaluation across the IT value chain," Proceedings of the Southern Association of Information Systems Conference, 2005.

18. Lomerson, W. and Hard, N., "Performance concepts for information technologist: Reexamining the components of productivity," Proceedings of the Information Resources Management Association Conference, 1994.

19. Markus, M. L. and C. Coh, "Banking on information technology: converting IT spending into firm performance," in R.D. Banker, R. J. Kauffman, and M. A. Mahmood (eds.) Strategic Information Technology Management: Perspectives on Organizational Growth and Competitive Advantage, Harrisburg, PA: Idea Group Publishing, 1993.

20. Melville, N, K.L. Kraemer, and V. Gurbaxani, "Information technology and organizational performance: An integrative model of IT business value,” MIS Quarterly, Vol. 28, No. 2, 283 - 322, 2004

21. Molla, A. and P. S. Licker, "E-commerce systems success: an attempt to extend and respecify the DeLone \& MaLean model of IS success," Journal of Electronic Commerce Research,” Vol. 2, No. 2, 1 - 11, 2001.

22. Panko, R., "Is office productivity stagnant?" MIS Quarterly, 191 - 203, June 1991.

23. Peppard, J and J. Ward, "Beyond strategic information systems: towards an IS capability," Journal of Strategic Information Systems, 13, 167 - 194, 2004.

24. Porra, Jaana, “The History of Texaco's Corporate Information Technology Function: A General Systems Theoretical Interpretation," MIS Quarterly, Vol. 29, No. 4, 721-746, 2005.

25. Rai, A., S. S. Lang, and R. B. Welker, "Assessing the validity of IS success models: an empirical test and theoretical analysis," Information Systems Research, Vol. 13, No. 1, $50-69,2002$.
26. Renekema, T. J., "Preface and outline of the book," in "The IT value quest: how to capture the business value of IT-based infrastructure," John Wiley \& Sons, 2000.

27. Sink, S.D., Productivity Management: Planning, Measurement and Evaluation, Control and Improvement, John Wiley \& Sons, New York, NY, 1985.

28. Soh, C. and M. L. Markus, "How IT creates business value: a process theory synthesis," Proceedings of International Conference on Information Systems, 1995.

29. Tanriverdi, H., "Information Technology Relatedness, Knowledge Management Capability, and Performance of Multibusiness Firms,” MIS Quarterly, Vol. 29, No. 2, 311-334, 2005.

30. Turner, J. A. "Organizational Performance, Size and the Use of Data Processing Resources." Working Paper Number 58, Center for Research on Information Sciences, Stern School of Business, New York University, 1983.

31. Weill, P. "The relationship between investment in information technology and firm performance: A study of the value manufacturing sector," Information Systems Review, Vol. 3, No. 4, 1992.

32. Weill, P. and M. Olson, "Managing investment in information technology: mini case examples and implications,” MIS Quarterly, Vol. 13, No. $1,1989$. 